\title{
Asymmetric Triangular Semi-Elliptic Slotted Patch Antennas for Wireless Applications
}

\author{
Naresh K. DARIMIREDDY ${ }^{1}$, R. RAMANA REDDY ${ }^{2}$, A. MALLIKARJUNA PRASAD ${ }^{3}$ \\ ${ }^{1}$ Dept. of ECE, Lendi IET, Vizianagaram, A.P., India \\ ${ }^{2}$ Dept. of ECE, MVGRCE (A), Vizianagaram, A.P., India \\ ${ }^{3}$ Dept. of ECE, UCEK (A), JNT University, Kakinada, A.P., India
}

yojitnaresh@gmail.com, profrrreddy@yahoo.co.in, a_malli65@yahoo.com

Submitted October 22, 2017 / Accepted January 23, 2018

\begin{abstract}
Microstrip radiators with Circular Polarization $(C P)$ are paid much attention in wireless and navigational applications. In this paper, four microstrip rectangular radiators with axially centered asymmetric TriangularSemi Elliptic (TSE) slots along the square boundary of the patch are proposed. The probe feed is applied along the diagonal of the square patch and it is optimized for its position to get $C P$ radiation. The first Asymmetric Slotted Patch (ASP\#1) of $50 \mathrm{~mm} \times 50 \mathrm{~mm}$ provides $10 \mathrm{~dB} R L$ (Return Loss) bandwidth of $200 \mathrm{MHz}(2320$ to $2520 \mathrm{MHz}$ ) with $\mathrm{CP}$ and $3 \mathrm{~dB}$ AR (Axial Ratio) bandwidth of $40 \mathrm{MHz}$ with a gain of $3.3 \mathrm{dBi}$. A 10dB RL bandwidth of $340 \mathrm{MHz}(2320$ to $2660 \mathrm{MHz}$ ) with $\mathrm{CP}$ and $3 \mathrm{~dB} A \mathrm{R}$ bandwidth of $60 \mathrm{MHz}$ (2370 to $2430 \mathrm{MHz}$ ) with a gain of $3.8 \mathrm{dBi}$ is obtained for the second Asymmetric Slotted Patch (ASP\#2) of $50 \mathrm{~mm} \times 50 \mathrm{~mm}$. The scale down versions of ASP\#2 presented are ASP\#3 $(40 \mathrm{~mm} \times 40 \mathrm{~mm})$ and ASP\#4 $(30 \mathrm{~mm} \times 30 \mathrm{~mm})$ suitable to operate in IEEE $802.11 \mathrm{y}$ (3.65-3.7 GHz) and 802.11a $(5.2 \mathrm{GHz}) \mathrm{Wi}$-Fi applications with $C P$ radiation. The proposed ASP\#3 offers $10 \mathrm{~dB} R L$ bandwidth of $390 \mathrm{MHz}, 3 \mathrm{~dB}$ AR bandwidth of $100 \mathrm{MHz}$ and a peak gain of $4.3 \mathrm{dBi}$ with CP. ASP\# 4 offers $10 \mathrm{~dB} R L$ bandwidth of $590 \mathrm{MHz}, 3 \mathrm{~dB}$ AR bandwidth of $160 \mathrm{MHz}$ and a peak gain of $3.95 \mathrm{dBi}$ with $C P$. It is evident from the results the proposed $A S P \# 1$ and $A S P \# 2$ are suitable for WLAN (2.4 GHz) and ISM (2.4-2.483 GHz) band applications. All the proposed four antennas are fabricated; measured results are compared with the simulation results.
\end{abstract}

\section{Keywords}

Microstrip radiator, asymmetric slot, symmetric slot, CP radiation, WLAN, TSE-slot

\section{Introduction}

For portable wireless and handheld devices circularly polarized antennas with good axial ratio bandwidth are in great demand. Generally patch antennas have narrow bandwidth, typically $1-5 \%$, which is the primary limitation for the extensive applications of these antennas. Broad bandwidth of patch antennas has been the main thrust area of research in this field. To avoid misalignment between the wireless devices, CP antennas are needed. The importance of one and double point $\mathrm{CP}$ patch feeds in mobile and satellite communication applications are addressed [1]. Regardless of good AR and CP bandwidth, dual-point feed antennas need feed network and occupy more space. Hence the advantages of single point $\mathrm{CP}$ radiators acknowledged more attention [2]. Circularly polarized elliptical-shaped printed antenna with varying eccentricities is proposed with an experimental study on impedance and radiation pattern [3].

Optimization and analysis of single point feed CP square patch antennas with trunked corners, diagonal feed and slot are described using Green's function and the desegmentation approaches [4]. A nearly square micro strip patch fed by strip line at the corner is proposed for circular polarization with a $3 \mathrm{~dB}$ AR bandwidth of $14 \mathrm{MHz}$ [5]. A corner truncated square patch with L-shaped slot and an L-shaped line feed with shorting via is used to obtain wideband CP radiation [6]. A circularly polarized square ring and crossed-strip patch antenna is reported based on segmentation technique coupled with cavity model [7]. A novel circularly polarized Fabry-Perot (FP) resonator patch antenna with mushroom-like Energy Band-Gap (EBG) structure and a two-layer LC superstrate is proposed for narrow band applications [8]. A proximity coupled compact and low profile CP antenna with unequal slot lengths of cross slot configuration is proposed for satellite applications [9]. The practical results show that it has good axial ratio and impedance bandwidth responses. A single feed, polarization and frequency reconfigurable corner trimmed square patch with PIN diodes and conducting strips is reported [10]. Many techniques like a tuning stub [11], embedded cross slot on radiating patch as well as on the ground plane [12], protruded curved edge rectangular patch [13], symmetric slit loaded patch [14], three layer cross slot coupled patch [15] and meshed patch [16] antennas are proposed for $\mathrm{CP}$ radiation.

A feeding system based on electromagnetic coupling for flat and reflect arrays using microstrip patches is pre- 
sented [17]. CPW fed compact slot antenna [18] is proposed for indoor wireless applications. By embedding nine cross slots, there is significant improvement in beam-width and reduction in antenna size [19]. The indentation parameter of pre-fractal curves along the fractal boundary of square patch is optimized for CP operation for WLAN applications [20]. A double layer circular patch comprising two stubs and a parasitic ring right above the patch to obtain half power beam-width of $140^{\circ}$ with circular polarization is reported [21]. A compact dodecagonal $2.45 \mathrm{GHz}$ patch with a polygonal slot [22] is proposed for wideband $\mathrm{CP}$ radiation. PIN diodes on the radiator [23] are used for polarization diversity, which is either Linearly Polarized (LP), left or right circularly polarized at each port. A CP radiated cross aperture coupled compact antenna [24] is reported with shorting strips and pins to reduce the overall dimensions of the radiator compared to the conventional antenna.

Lower AR value is required to achieve better $\mathrm{CP}$ radiation. Combined advantages of lower AR value, AR bandwidth and $\mathrm{CP}$ radiation are very much in need for portable wireless communication and navigational systems. In open literature different designs of antennas with $\mathrm{CP}$ radiation are reported. It is evident from the open literature there is need for design of miniaturized $\mathrm{CP}$ antennas working in the range of 2-6 GHz with low AR value and high AR bandwidth for wireless applications.

In this paper focus is on design of $\mathrm{CP}$ antennas with low AR value, sufficient AR bandwidth and gain. Four Asymmetric Slotted Patch (ASP) antennas with CP are presented in this paper for WLAN $(2.4 \mathrm{GHz} / 5.2 \mathrm{GHz})$ and ISM band applications.

\section{Asymmetric Slotted Patch (ASP)}

The effective length of the square patch can be enhanced by incorporating slots along the boundary and also miniaturization can be done efficiently. The fundamental resonant frequency $\left(f_{\text {res }}\right)$ or corresponding effective length $\left(L_{\text {eff }}\right)$ can be obtained for the rectangular or square patch antennas from (1) and (2) given below,

$$
\begin{aligned}
& L_{\text {eff }}=L+2 \Delta L=\frac{\lambda_{0}}{2 \sqrt{\varepsilon_{\text {reff }}}}=\frac{c}{2 f_{\text {res }} \sqrt{\varepsilon_{\text {reff }}}}, \\
& \varepsilon_{\text {reff }} \cong\left(\frac{\varepsilon_{\mathrm{r}}+1}{2}\right)
\end{aligned}
$$

where $\lambda_{0}$ is free space wavelength, $c$ is free space light velocity, $\varepsilon_{\text {reff }}$ is effective dielectric constant, and $L$ is the length of the square patch and $\Delta L$ is the extension of length on the account of fringing. The proposed square patch antenna dimension is of $50 \mathrm{~mm} \times 50 \mathrm{~mm}$ with a RT/ Duroid $5880\left(\varepsilon_{\mathrm{r}}=2.2\right)$ substrate of thickness $3.175 \mathrm{~mm}$. The size of the radiating element is $36 \mathrm{~mm} \times 36 \mathrm{~mm}$.

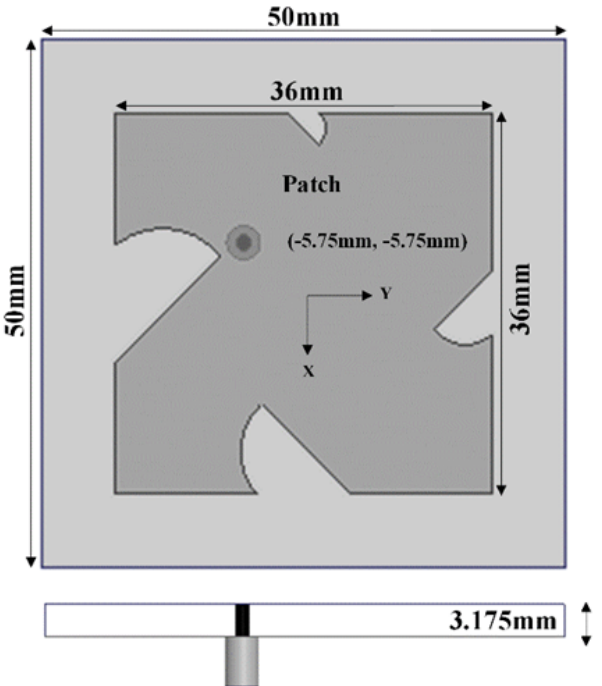

(a)

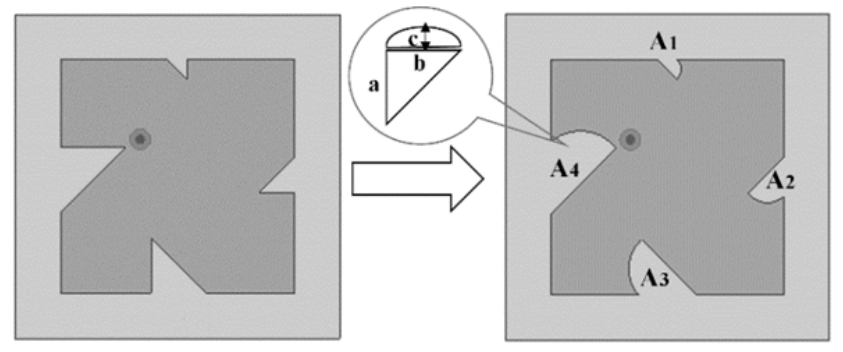

(b)

Fig. 1. (a) Proposed asymmetric patch configuration. (b) Generation of ASP \#1.

\begin{tabular}{|c|c|c|c|c|}
\hline Antenna & Designation & $\mathbf{a}(\mathbf{m m})$ & $\mathbf{b}(\mathbf{m m})$ & $\mathbf{c}(\mathbf{m m})$ \\
\hline \multirow{3}{*}{ ASP\#1 } & $A_{1}$ & 3 & 3 & 0.65 \\
\cline { 2 - 5 } & $A_{2}$ & 6 & 5.5 & 1.5 \\
\cline { 2 - 5 } & $A_{3}$ & 9 & 8.5 & 2 \\
\cline { 2 - 5 } & $A_{4}$ & 11 & 10 & 2.5 \\
\hline \multirow{2}{*}{ ASP\#2 } & $A_{1}$ & 4 & 4 & 1 \\
\cline { 2 - 5 } & $A_{2}$ & 8 & 8 & 2 \\
\hline
\end{tabular}

Tab. 1. Designated TSE slot dimensions.

\section{Configuration and Design of ASP\#1}

Miniaturization of an antenna can be done by adding shorting posts and cutting different slots. Four unequal right angle triangles are subtracted from all the sides (axially centered) of square patch and then four semi elliptic slots are etched as shown in Fig. 1(a), (b). The areas of TSE slots are taken in such a way that $A_{1}<A_{2}<A_{3}<A_{4}$. The TSE-slot dimensions considered are presented in Tab. 1.

\subsection{CP Radiation Principle of ASP\#1}

The study of CP radiation and its principle of generation for ASP\#1 is presented in this section. To generate $\mathrm{CP}$, an asymmetry is created in the structure by cutting four unequal axially centered TSE slots $\left(A_{1}<A_{2}<A_{3}<A_{4}\right)$ along 


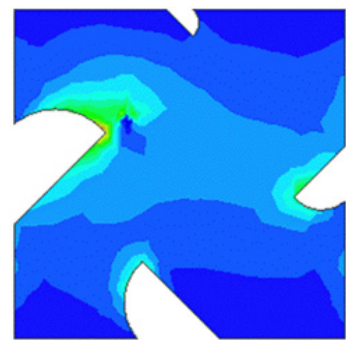

(a)

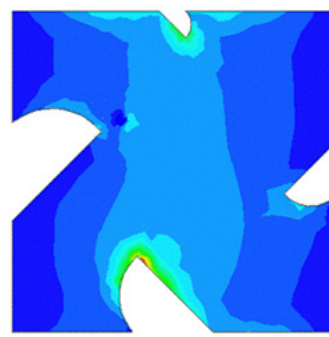

(c)

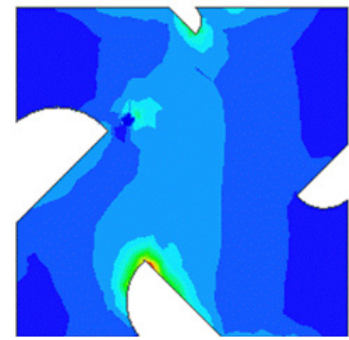

(b)
Fig. 2. Distribution of surface current at $2.36 \mathrm{GHz}$ with different phases.

square boundary of patch with probe feed on the diagonal of XY-plane. For circular polarization, the proposed asymmetric-patch should operate in two orthogonal modes with the same magnitude and difference in phase of $90^{\circ}$. The time varying surface current distribution analysis of the proposed ASP\#1 is shown in Fig. 2 at different phases $\left(0^{\circ}, 45^{\circ}, 90^{\circ}\right.$, and $\left.135^{\circ}\right)$. The dominance of distribution of surface current concentrated at the incorporated TSE slots. The clear observation of circular distribution (anti-clockwise) of surface current density confirms the Left Hand Circular Polarization (LHCP) radiation.

\subsection{3dB Axial Ratio Beam-Width}

The $3 \mathrm{~dB}$ axial ratio beam-width of the ASP\#1 is plotted in Fig. 3 for both the standard XZ- and YZ-planes at $2.36 \mathrm{GHz}$ and it is around $125^{\circ}$ and $145^{\circ}$ respectively. Therefore, along with LHCP principle, the proposed ASP\#1 can cover more than $125^{\circ}$ beam-width towards the sky.

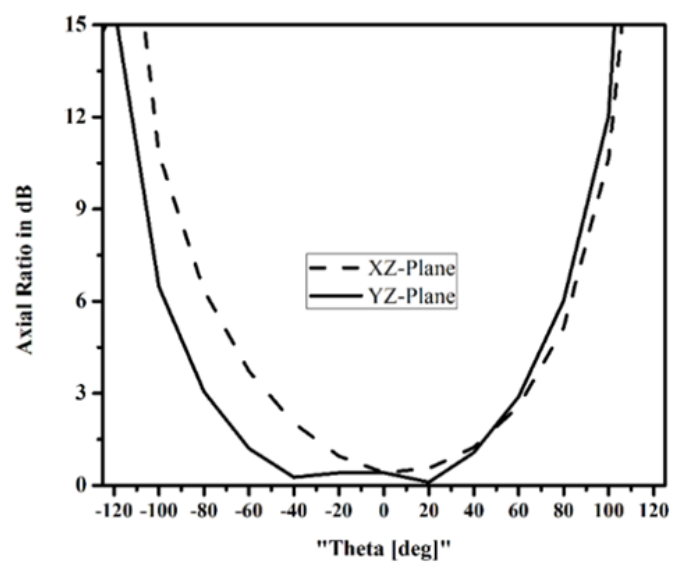

Fig. 3. $3 \mathrm{~dB}$ AR beam-width of ASP\#1.

\section{Parametric Studies for ASP\#1}

The parametric study is performed to study the performance of the proposed ASP\#1 by varying feed position, generation of TSE-slot, axial ratio variations for different TSE-slot areas and the effect of dimensions of the TSE slot. These studies are conducted with respect to one parameter, by keeping rest constant.

\subsection{Optimization of Feed Position}

The presented ASP\#1 is diagonally coax fed antenna. Different feed positions are attempted to find the feed point with good impedance match and less return loss. From the results presented in Fig. 4, it is evident that feed point $\mathrm{F}(-5.75 \mathrm{~mm},-5.75 \mathrm{~mm})$ is having good impedance match and the successive modes are orthogonal with maximum radiation and wider bandwidth compared to other feed positions.

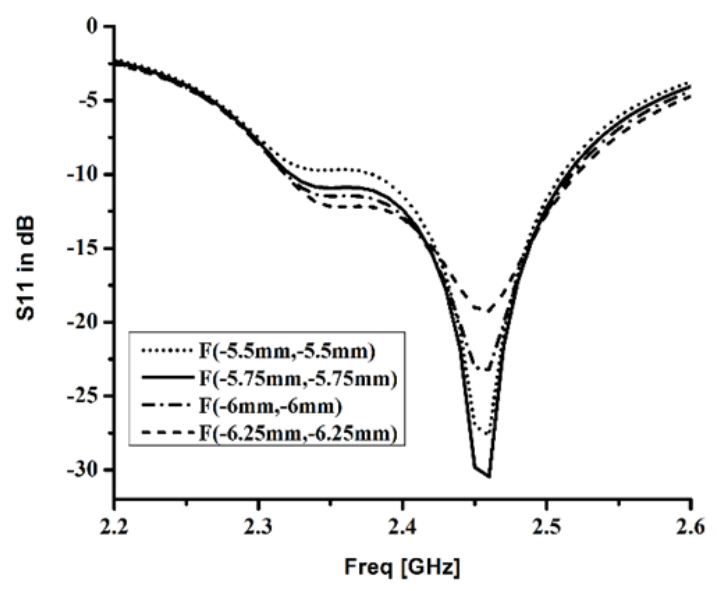

Fig. 4. S11 plot for different feed positions.

\subsection{Impact of TSE-Slot Generation}

From Fig. 5(a) the proposed TSE slot provides bandwidth of $200 \mathrm{MHz}$ compared to triangular slot of $180 \mathrm{MHz}$. The $\mathrm{AR}$ in $\mathrm{dB}$ is 0.1 for TSE-slot and 0.45 for triangular slot as shown in Fig. 5(b).

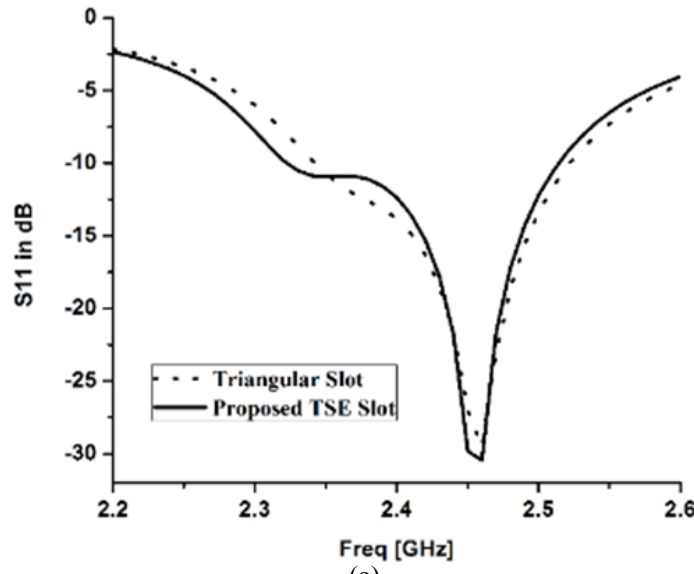

(a) 


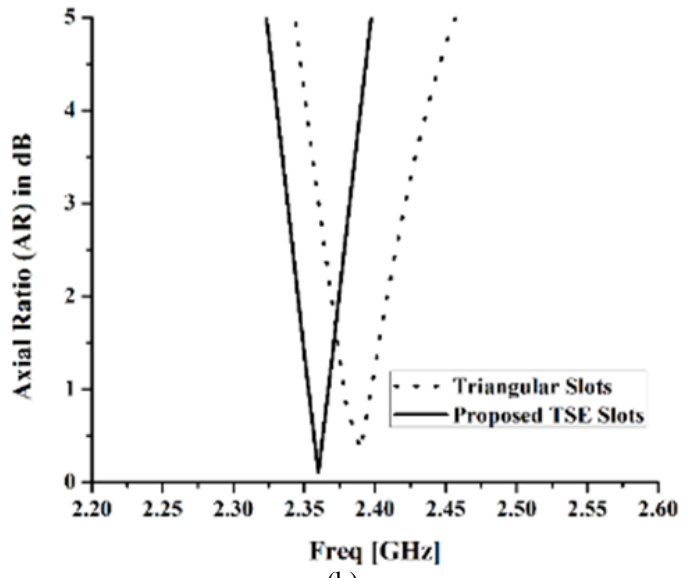

(b)

Fig. 5. Comparison of (a) S11 and (b) AR plots for Triangular and Proposed TSE slots.

Even though both triangular and TSE slots generates nearly same S11 and axial ratio, the curvature of the TSE slot provides more bandwidth. A maximum $3 \mathrm{~dB}$ beamwidth of $145^{\circ}$ is provided by the proposed TSE-ASP\#1.

\subsection{AR for Different TSE-Slot Areas}

Different areas of TSE slot are chosen to get better (lowest) $\mathrm{AR}$ in $\mathrm{dB}$ as shown in Fig. 6. The parametric study is conducted for three different slot areas, such as $\mathrm{X}: A_{2}=$ $2 A_{1}, A_{3}=3 A_{1}, A_{4}=4 A_{1} ; \mathrm{Y}: A_{2}=2 A_{1}, A_{3}=2.5 A_{1}, A_{4}>4 A_{1}$; Proposed: $A_{1}<A_{2}<A_{3}<A_{4}$. The proposed TSE-slot is having the lowest axial ratio of $0.1 \mathrm{~dB}$ at the desired frequency, compared to the other TSE slot areas designated as $\mathrm{X}$ and $\mathrm{Y}$.

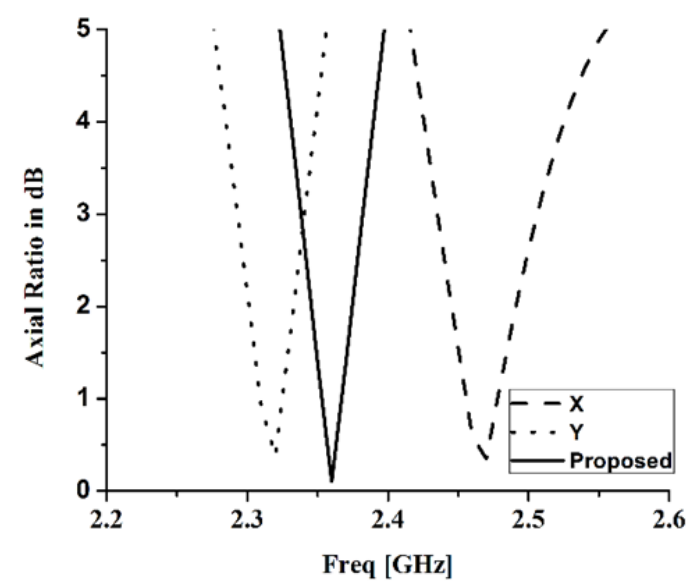

Fig. 6. AR plot for different areas of TSE slot.

\subsection{Effect of $a, b$ and $c$ Dimensions of TSE-Slot}

The effect of different TSE-slot dimensions $(a, b, c)$ on the minimum AR value and AR bandwidth is presented in Tab. 2(a)-(d). The parametric study is performed by varying one dimension ( $a$ or $b$ or $c$ ) of one slot (A1 or A2 or A3 or A4) and keeping all other dimensions of the slots constant. It is evident from the parametric analysis pre- sented in Tab. 2, the AR bandwidth offered by the proposed TSE-slot dimensions is $40 \mathrm{MHz}$, which is higher than the bandwidth with the lowest $\mathrm{AR}$ in $\mathrm{dB}$ offered by other variations in dimensions of $a$ or $b$ or $c$.

\begin{tabular}{|c|c|c|c|c|c|}
\hline & \multicolumn{3}{|c|}{ A1 } & \multirow{2}{*}{$\begin{array}{c}\text { AR } \\
(\mathrm{dB})\end{array}$} & \multirow{2}{*}{$\begin{array}{c}\text { AR BW } \\
\text { (MHz) }\end{array}$} \\
\hline & $a(\mathbf{m m})$ & $b(\mathbf{m m})$ & $c(\mathbf{m m})$ & & \\
\hline \multirow{3}{*}{ 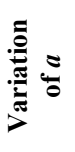 } & 2 & 3 & 0.65 & 1 & 35 \\
\hline & 3 & 3 & 0.65 & 0.1 & 40 \\
\hline & 4 & 3 & 0.65 & 0.9 & 38 \\
\hline \multirow{3}{*}{ 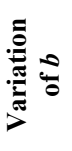 } & 3 & 2 & 0.65 & 1.5 & 40 \\
\hline & 3 & 3 & 0.65 & 0.1 & 40 \\
\hline & 3 & 4 & 0.65 & 2 & 30 \\
\hline \multirow{3}{*}{ نّ } & 3 & 3 & 0.15 & 2.5 & 25 \\
\hline & 3 & 3 & 0.65 & 0.1 & 40 \\
\hline & 3 & 3 & 1.15 & 1.9 & 36 \\
\hline
\end{tabular}

(a) Variations in $\mathrm{a}, \mathrm{b}$ and $\mathrm{c}$ dimensions of $\mathrm{A} 1$, keeping rest ( $a, b$ and $c$ of $\mathrm{A} 2, \mathrm{~A} 3$ and $\mathrm{A} 4)$ constant.

\begin{tabular}{|c|c|c|c|c|c|}
\hline & \multicolumn{3}{|c|}{ A2 } & \multirow{2}{*}{$\begin{array}{c}\text { AR } \\
(\mathrm{dB})\end{array}$} & \multirow{2}{*}{$\begin{array}{c}\text { AR BW } \\
\text { (MHz) }\end{array}$} \\
\hline & $a(\mathrm{~mm})$ & $b(\mathrm{~mm})$ & $c(\mathbf{m m})$ & & \\
\hline \multirow{3}{*}{ 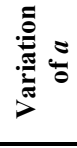 } & 5 & 5.5 & 1.5 & 0.9 & 34 \\
\hline & 6 & 5.5 & 1.5 & 0.1 & 40 \\
\hline & 7 & 5.5 & 1.5 & 2 & 30 \\
\hline \multirow{3}{*}{ مै } & 6 & 4.5 & 1.5 & 0.5 & 32 \\
\hline & 6 & 5.5 & 1.5 & 0.1 & 40 \\
\hline & 6 & 6.5 & 1.5 & 1.6 & 26 \\
\hline \multirow{3}{*}{ 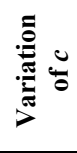 } & 6 & 5.5 & 1.0 & 1.4 & 40 \\
\hline & 6 & 5.5 & 1.5 & 0.1 & 40 \\
\hline & 6 & 5.5 & 2 & 1.8 & 30 \\
\hline
\end{tabular}

(b) Variations in $a, b$ and $c$ dimensions of $\mathrm{A} 2$, keeping rest ( $a, b$ and $c$ of $\mathrm{A} 1, \mathrm{~A} 3$ and $\mathrm{A} 4$ ) constant.

\begin{tabular}{|c|c|c|c|c|c|}
\hline & \multicolumn{3}{|c|}{ A3 } & \multirow{2}{*}{$A R(d B)$} & \multirow{2}{*}{$\begin{array}{c}\text { AR BW } \\
(\mathrm{MHz})\end{array}$} \\
\hline & $a(\mathrm{~mm})$ & $b(\mathrm{~mm})$ & $c(\mathbf{m m})$ & & \\
\hline \multirow{3}{*}{ 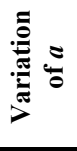 } & 8 & 8.5 & 2 & 1.8 & 30 \\
\hline & 9 & 8.5 & 2 & 0.1 & 40 \\
\hline & 10 & 8.5 & 2 & 2.8 & 15 \\
\hline \multirow{3}{*}{ 莞 } & 9 & 7.5 & 2 & 1 & 40 \\
\hline & 9 & 8.5 & 2 & 0.1 & 40 \\
\hline & 9 & 9.5 & 2 & 2.2 & 20 \\
\hline \multirow{3}{*}{ 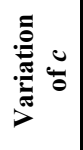 } & 9 & 8.5 & 1.5 & 1.2 & 25 \\
\hline & 9 & 8.5 & 2 & 0.1 & 40 \\
\hline & 9 & 8.5 & 2.5 & 2 & 35 \\
\hline
\end{tabular}

(c) Variations in $a, b$ and $c$ dimensions of A3, keeping rest ( $a, b$ and $c$ of A1, A2 and A4) constant. 


\begin{tabular}{|c|c|c|c|c|c|}
\hline & \multicolumn{3}{|c|}{ A4 } & \multirow{2}{*}{$A R(d B)$} & \multirow{2}{*}{$\begin{array}{c}\text { AR BW } \\
\text { (MHz) }\end{array}$} \\
\hline & $a(\mathrm{~mm})$ & $b(\mathbf{m m})$ & $c(\mathbf{m m})$ & & \\
\hline \multirow{3}{*}{ 递 } & 10 & 10 & 2.5 & 0.8 & 25 \\
\hline & 11 & 10 & 2.5 & 0.1 & 40 \\
\hline & 12 & 10 & 2.5 & 1.4 & 30 \\
\hline \multirow{3}{*}{ 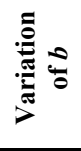 } & 11 & 9 & 2.5 & 1.1 & 34 \\
\hline & 11 & 10 & 2.5 & 0.1 & 40 \\
\hline & 11 & 11 & 2.5 & 2 & 15 \\
\hline \multirow{3}{*}{ ن } & 11 & 10 & 2 & 1 & 35 \\
\hline & 11 & 10 & 2.5 & 0.1 & 40 \\
\hline & 11 & 10 & 3 & 0.6 & 40 \\
\hline
\end{tabular}

(d) Variations in $a, b$ and $c$ dimensions of A4, keeping rest ( $a, b$ and $c$ of $\mathrm{A} 1, \mathrm{~A} 2$ and $\mathrm{A} 3$ ) constant.

Tab. 2. Effect of $a, b$ and $c$ dimensions on all the TSE-slots.

\section{Configuration and Design of ASP\#2}

The second Asymmetric Slotted Patch (ASP)\#2 is a $\mathrm{CP}$ antenna with same dimensions as ASP\#1. The modification in ASP\#2 is that the slots are etched according to the relation $A_{2}=2 A_{1}$ as shown in Fig. 7, where the opposite TSE slot areas are equal.

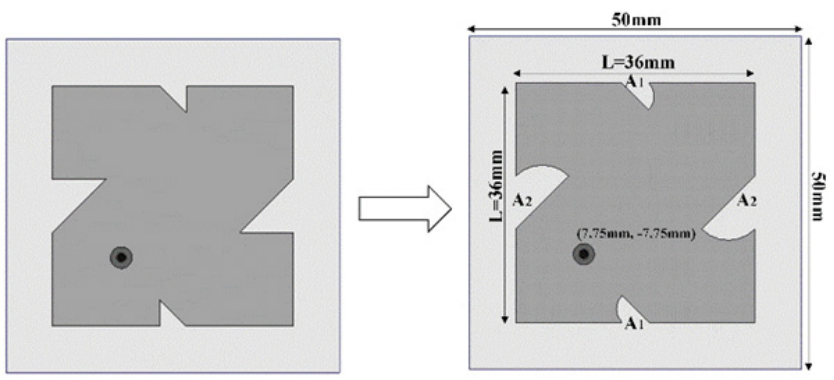

Fig. 7. Proposed Asymmetric Slotted Patch (ASP) \#2.

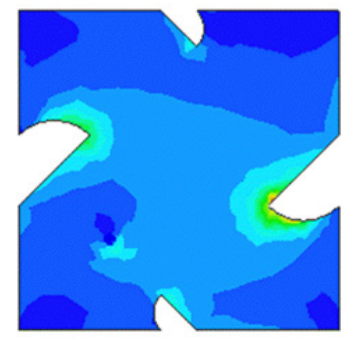

(a)

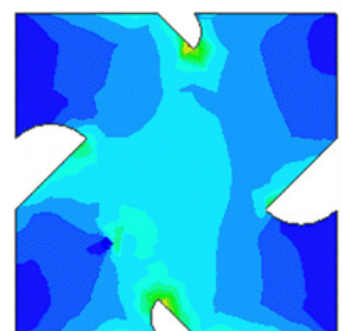

(c)

Fig. 8. Distribution of surface current at $2.4 \mathrm{GHz}$ with time dependent phases.

\subsection{CP Radiation Principle of ASP\#2}

Two orthogonal modes with $90^{\circ}$ phase difference and equal magnitude is required for $\mathrm{CP}$ radiation. By etching equal area TSE slots (odd symmetry with respect to origin), along the boundary of square patch with coax-feed on the diagonal of XY-plane, $\mathrm{CP}$ is achieved.

The dominant current density at TSE slots with respect to different phases $\left(0^{\circ}, 45^{\circ}, 90^{\circ}\right.$, and $\left.135^{\circ}\right)$ is represented in Fig. 8. The anti-clockwise rotation of current density distribution endorses the LHCP radiation.

\section{Parametric Study of ASP\#2}

The performance parameters of the ASP\#2 are obtained through parametric studies of feed position, impact of TSE-slot, axial ratio variations for different TSE-slot areas and impact of dimensions of the TSE slot.

\subsection{Optimization of Feed Position}

The ASP\#2 is coax fed antenna and it is applied on the diagonal of the square patch. S11 for different feed positions are presented in Fig. 9. From the results it can be observed that feed point $\mathrm{F}(7.75 \mathrm{~mm},-7.75 \mathrm{~mm})$ offers good impedance match and maximum radiation.

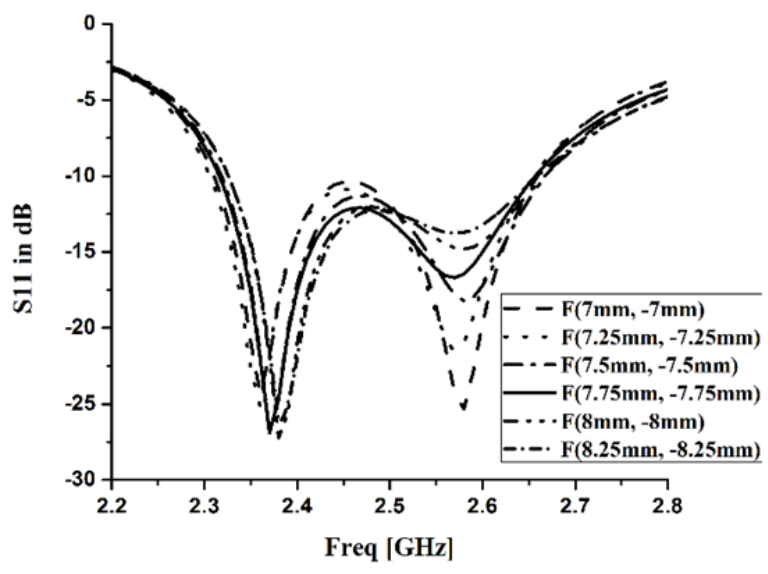

Fig. 9. S11 plot for different feed positions for ASP\#2

\subsection{Impact of TSE-Slot}

It is evident from Fig. 10(a), the proposed ASP\#2 has wider bandwidth of $340 \mathrm{MHz}$ compared to triangular slot of $290 \mathrm{MHz}$. The AR in $\mathrm{dB}$ is 0.2 for TSE-slot and 0.35 for triangular slot as shown in Fig. 10(b).

\subsection{AR for Different TSE Slot Areas}

Different TSE-slot areas are considered in Fig. 11 to optimize the proposed TSE slot to obtain the lowest axial ratio $0.2 \mathrm{~dB}$ at $2.4 \mathrm{GHz}$. The $3 \mathrm{~dB}$ AR bandwidth obtained for $A_{2}<2 A_{1}$ is $50 \mathrm{MHz}$ ( 2310 to $2360 \mathrm{MHz}$ ). For the proposed TSE slot area $A_{2}=2 A_{1}$, the $3 \mathrm{~dB}$ AR bandwidth obtained is $60 \mathrm{MHz}$ (2370 to $2430 \mathrm{MHz}$ ). 


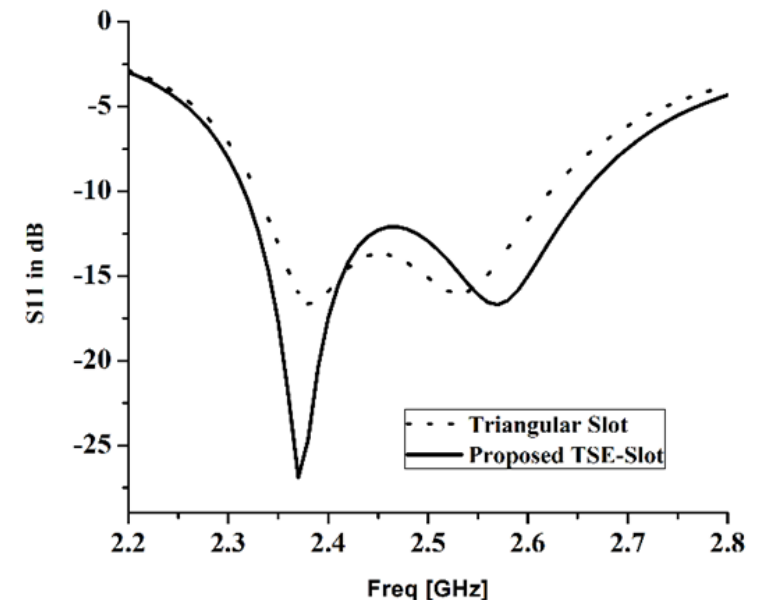

(a)

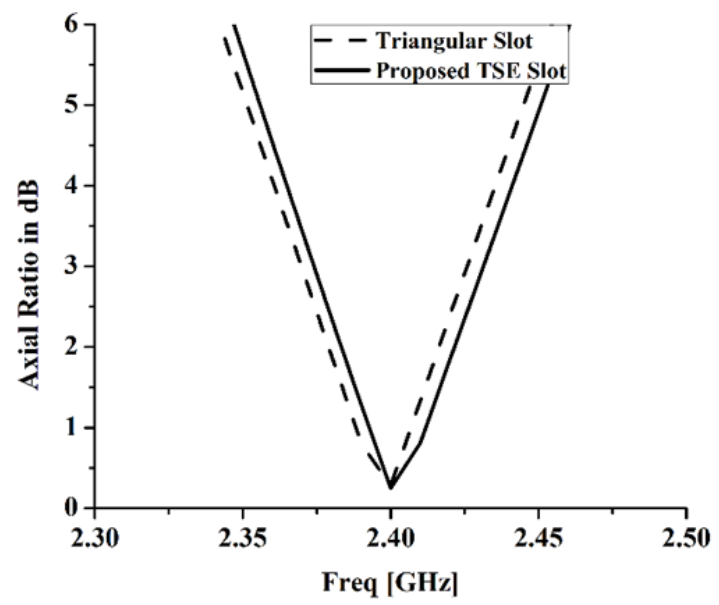

(b)

Fig. 10. Comparison of (a) S11, (b) AR plots for triangular and proposed TSE slots.

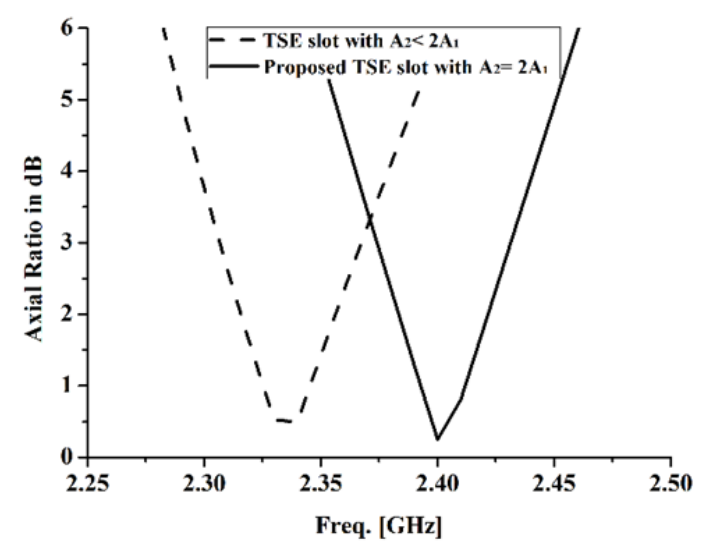

Fig. 11. Comparison of AR for different TSE slot areas.

\subsection{Impact of $a, b$ and $c$ on TSE-Slot}

Similar to ASP\#1, parametric analysis to find the impact of different TSE-slot dimensions $(a, b, c)$ on AR value and AR bandwidth is done for ASP\#2. The AR bandwidth offered for the proposed TSE-slot dimensions is $60 \mathrm{MHz}$ and $\mathrm{AR}$ in $\mathrm{dB}$ is 0.2 , which are better than the other TSEslot variations with respect to the dimensions of $(a, b, c)$.
The final design dimensions are obtained through parametric studies and surface current analysis of the ASP\#1 and ASP\#2. Similarly, the parametric studies and surface current analysis are also conducted on scaled down versions ASP\#3 $(40 \mathrm{~mm} \times 40 \mathrm{~mm})$ and ASP\#4 $(30 \mathrm{~mm} \times 30 \mathrm{~mm})$. The proposed ASP\#3 offers $10 \mathrm{~dB} \mathrm{RL}$ bandwidth of $390 \mathrm{MHz}, 3 \mathrm{~dB}$ AR bandwidth of $100 \mathrm{MHz}$ and a peak gain of $4.3 \mathrm{dBi}$ with $\mathrm{CP}$ radiation. ASP\#4 offers $10 \mathrm{~dB}$ RL bandwidth of $590 \mathrm{MHz}, 3 \mathrm{~dB}$ AR bandwidth of $160 \mathrm{MHz}$ and a peak gain of $3.95 \mathrm{dBi}$ with $\mathrm{CP}$ radiation.

\section{Discussion of Measured Results}

All the proposed four antennas are fabricated and presented in Fig. 12(a), (b). The S11 is measured using Agilent Vector Network Analyzer (VNA) E5071C and comparison with simulation results are presented in Fig. 13(a), (b). The antennas are tested in an anechoic chamber for radiation pattern, axial ratio and peak gain. The setup in anechoic chamber is shown in Fig. 14 and measured results are presented in Fig. 15 and Fig. 16. Pattern plots are similar in both the orthogonal planes at the corresponding CP resonant frequency, where both modes are in equal magnitude and $90^{\circ}$ phase difference indicates $\mathrm{CP}$ radiation.

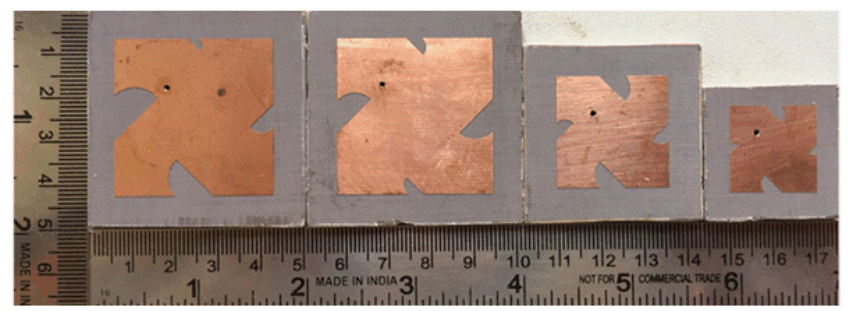

(a)

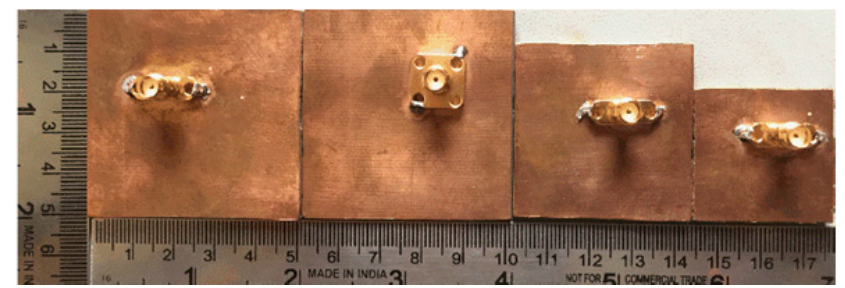

(b)

Fig. 12. Fabricated antenna structures: (a) Front view. (b) Rear view.

The simulated and measured radiation efficiency presented in Fig. 17 is above $90 \%$ at the circularly polarized frequency of resonance for the proposed antennas. It is evident from the results the simulated and measured results are in close agreement. The consistency between simulations and measurements may be, in general difficult for narrow band responses for return losses and AR. The small deviations in practical results when compared to simulation results are attributed to fabrication tolerances, which are not considered in the process of simulation.

The performance comparison between the proposed designs and the other types of noble structures [20]-[24] pertaining to overall size, operating frequency range, $10 \mathrm{~dB}$ 


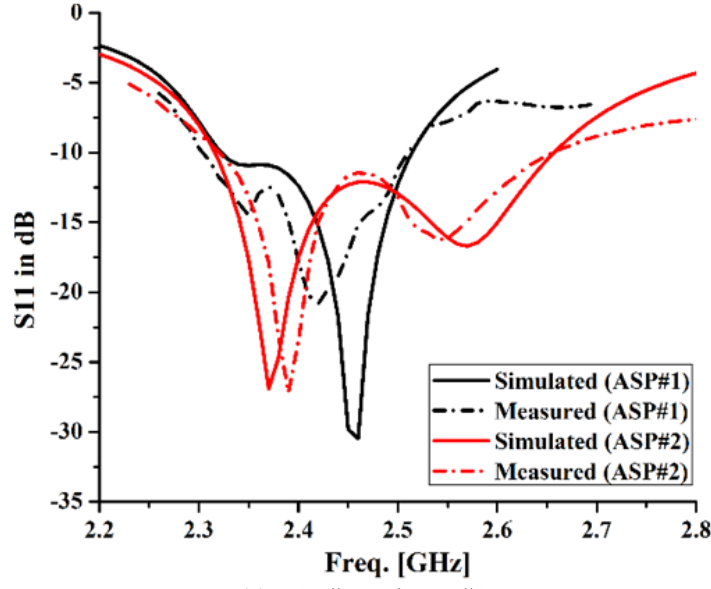

(a) ASP\#1 and ASP\#2

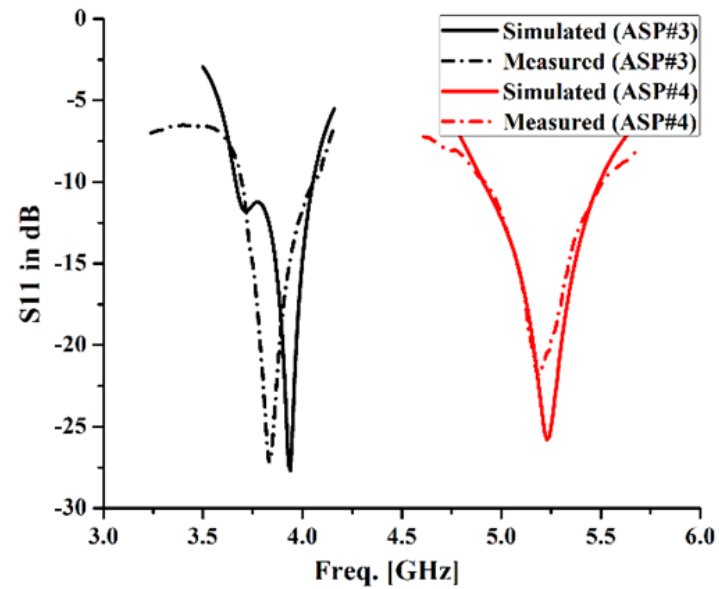

(b) ASP\#3 and ASP\#4

Fig. 13. Comparison of simulated and measured $\mathrm{S} 11$ for all the four ASPs.

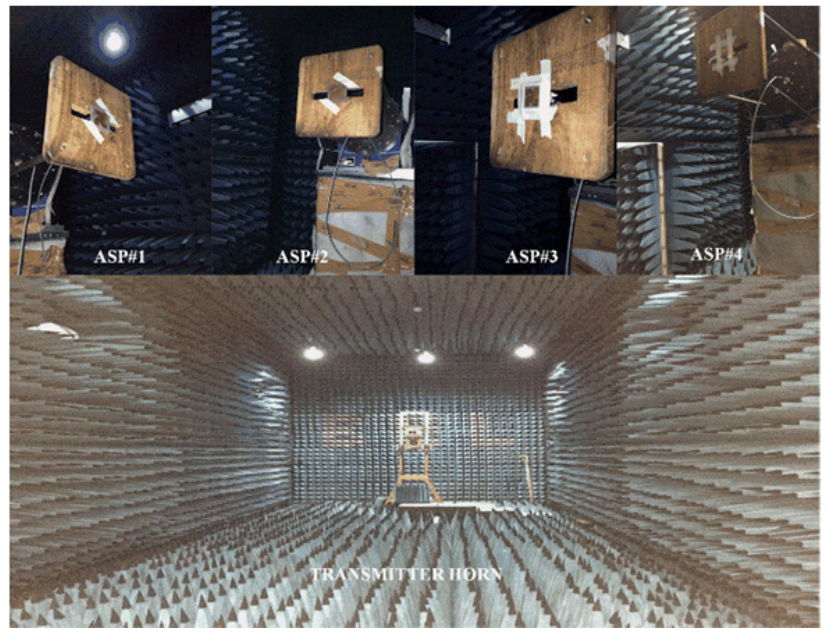

Fig. 14. Pattern and gain measurement in an anechoic chamber.

return loss bandwidth, $3 \mathrm{~dB}$ AR bandwidth and peak gain is presented in Tab. 3. The proposed antennas are smaller in size, have higher $10 \mathrm{~dB}$ bandwidth, $3 \mathrm{~dB}$ AR bandwidth and reasonable gain to operate in WLAN, ISM and Wi-Fi applications. The percentage $10 \mathrm{~dB}$ RL bandwidth is $8.3 \%$, $13.7 \%, 10.2 \%$ and $11.4 \%$ for ASP\#1 to ASP\#4, respectively. $3 \mathrm{~dB}$ AR bandwidth percentage for ASP\#1 to ASP\#4 is $1.7 \%, 2.5 \%, 2.65 \%$ and $3.3 \%$, respectively. Novelty of

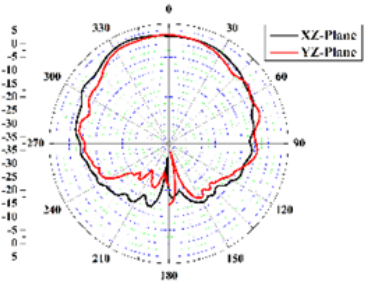

(a) $\mathrm{ASP} \# 1(2.36 \mathrm{GHz})$

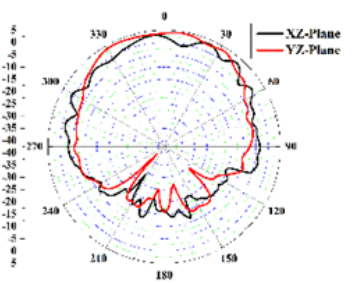

(c) $\operatorname{ASP} \# 3(3.8 \mathrm{GHz})$

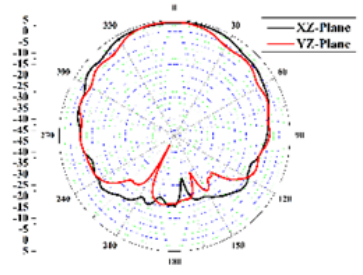

(b) ASP\#2 (2.4 GHz)

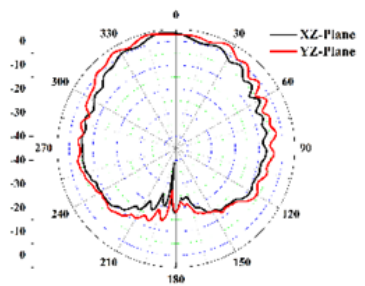

(d) ASP\#4 (4.9 GHz)
Fig. 15. Measured radiation patterns of two orthogonal planes (XZ and YZ planes).

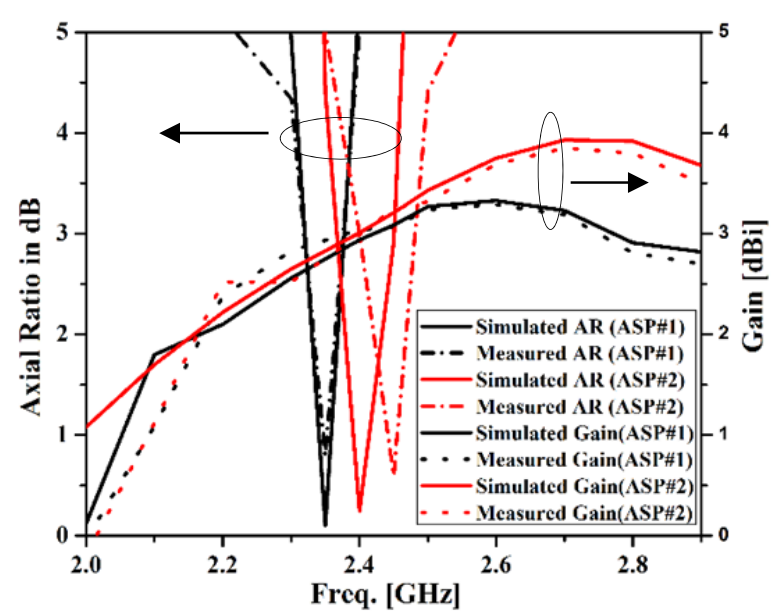

(a) ASP\#1 and ASP\#2

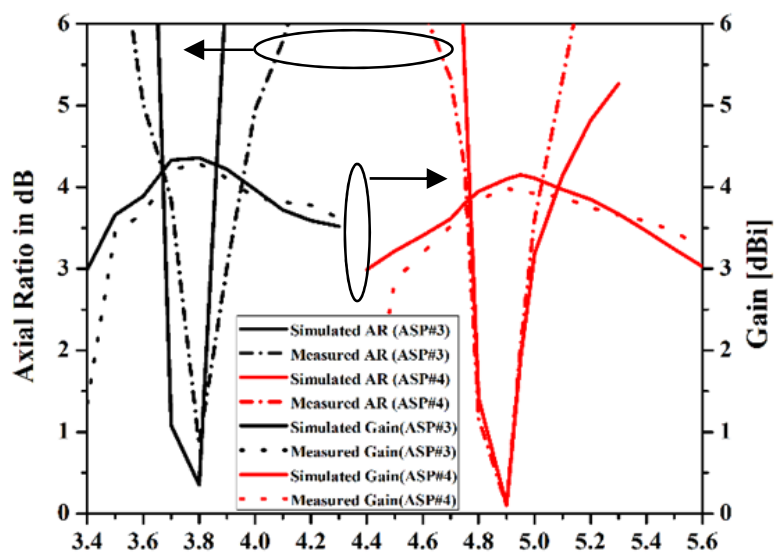

Freq. $[\mathrm{GHz}]$

(b) ASP\#3 and ASP\#4

Fig. 16. Comparison between simulated and measured peak gains along with axial ratios for all four ASPs.

the proposed design is by scaling down the dimensions appropriately, AR bandwidth can be enhanced from $40 \mathrm{MHz}$ to $160 \mathrm{MHz}$ in the span of 2 to $6 \mathrm{GHz}$ frequency range with minimum $A R$ value, through which one can attain better $\mathrm{CP}$ radiation. 


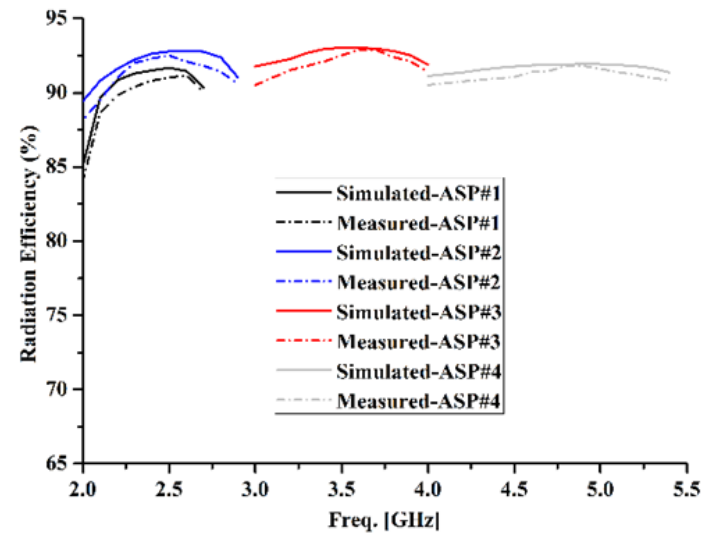

Fig. 17. Comparison between simulated and measured radiation efficiency for all four ASPs.

\begin{tabular}{|c|c|c|c|c|c|}
\hline Ref. & $\begin{array}{c}\text { Size } \\
\left(\mathbf{m m}^{2}\right)\end{array}$ & $\begin{array}{c}\text { Operating } \\
\text { Frequency } \\
\text { Range } \\
\text { (MHz) }\end{array}$ & $\begin{array}{c}\text { 10dB } \\
\text { RL BW } \\
\text { (MHz) }\end{array}$ & $\begin{array}{c}\text { 3dB AR } \\
\text { BW } \\
\text { (MHz) }\end{array}$ & $\begin{array}{c}\text { Gain } \\
(\mathbf{d B i})\end{array}$ \\
\hline$[20]$ & $42 \times 42$ & $2455-2617$ & 162 & 50 & 6 \\
\hline$[21]$ & $68 \times 68$ & $2468-2498$ & 30 & 7 & 3.4 \\
\hline$[22]$ & $50 \times 50$ & $2350-2490$ & 140 & 135 & 4.82 \\
\hline$[23]$ & $80 \times 80$ & $2250-2460$ & 210 & 50 & 6.1 \\
\hline$[24]$ & $50 \times 50$ & $1886-1978$ & 92 & 28 & 4.9 \\
\hline $\begin{array}{c}\text { Proposed } \\
\text { ASP\#1 }\end{array}$ & $50 \times 50$ & $2320-2520$ & 200 & 40 & 3.3 \\
\hline $\begin{array}{c}\text { Proposed } \\
\text { ASP\#2 }\end{array}$ & $50 \times 50$ & $2320-2660$ & 340 & 60 & 3.8 \\
\hline $\begin{array}{c}\text { Proposed } \\
\text { ASP\#3 }\end{array}$ & $40 \times 40$ & $3670-4050$ & 390 & 100 & 4.3 \\
\hline $\begin{array}{c}\text { Proposed } \\
\text { ASP\#4 }\end{array}$ & $30 \times 30$ & $4900-5490$ & 590 & 160 & 3.95 \\
\hline
\end{tabular}

Tab. 3. Performance comparison.

\section{Conclusion}

Four Circularly Polarized slotted microstrip radiators are proposed in this paper. TSE (Triangular Semi-Elliptic) slots are used along the periphery of the square patch to create asymmetry in the structure for circular polarization. From the results it is evident that ASP\#1 has 10dB RL bandwidth of $200 \mathrm{MHz}$ with $\mathrm{CP}, 3 \mathrm{~dB}$ AR bandwidth of $40 \mathrm{MHz}$ and a maximum $3 \mathrm{~dB}$ beam width of $145^{\circ}$ with a gain of $3.3 \mathrm{dBi}$. A $10 \mathrm{~dB} \mathrm{RL}$ bandwidth of $340 \mathrm{MHz}$ with $\mathrm{CP}$ and $3 \mathrm{~dB}$ AR bandwidth of $60 \mathrm{MHz}$ (2.37 to $2.43 \mathrm{GHz}$ ) with a gain of $3.8 \mathrm{dBi}$ are obtained for ASP\#2. A $10 \mathrm{~dB}$ bandwidth of $390 \mathrm{MHz}$ and $590 \mathrm{MHz}, 3 \mathrm{~dB}$ AR bandwidth of $100 \mathrm{MHz}$ and $160 \mathrm{MHz}$, peak gain of $4.3 \mathrm{dBi}$ and $3.95 \mathrm{dBi}$ respectively are obtained for ASP\#3 and ASP\#4. It is apparent from the results that the proposed ASP\#1 and ASP\#2 are suitable for WLAN $(2.4 \mathrm{GHz})$ and ISM (2.4 to $2.483 \mathrm{GHz}$ ) applications. The scaled down versions
(ASP\#3 and ASP\#4) are designed to work in IEEE $802.11 \mathrm{y}$ $(3.65-3.7 \mathrm{GHz})$ and $802.11 \mathrm{a}(5.2 \mathrm{GHz}) \mathrm{Wi}-\mathrm{Fi}$ applications. The measured results are in close agreement with the simulation results.

\section{References}

[1] SHARMA, S. K., RAO S., SHAFAI, L. (Eds.) Handbook of Reflector Antennas and Feed Systems. Vol. 1. London (UK): Artech House, 2013. ISBN-13: 978-1608075157

[2] GUHA, D., ANTAR, Y. M. M. (Eds.) Microstrip and Printed Antennas: New Trends, Techniques and Applications. UK: John Wiley \& Sons, 2011. ISBN: 978-1-119-97298-3

[3] LONG, S. A., SHEN, L. C., SCHAUBERT, D. H., FARRAR, F.G. An experimental study of the circular-polarized elliptical printedcircuit antenna. IEEE Transactions on Antennas and Propagation, 1981, vol. 29, no. 1, p. 95-99. DOI: 10.1109/TAP.1981.1142549

[4] SHARMA, P. C., GUPTA, K. C. Analysis and optimized design of single feed circularly polarized microstrip antennas. IEEE Transactions on Antennas and Propagation, 1983, vol. 31, no. 6, p. 949-955. DOI: 10.1109/TAP.1983.1143162

[5] DESHPANDE, M. D., DAS, N. K. Rectangular microstrip antenna for circular polarization. IEEE Transactions on Antennas and Propagation, 1986, vol. 34, no. 6, p. 744-746. DOI: 10.1109/TAP.1986.1143886

[6] YANG, S.L.S., KISHK, A. A., LEE, K. F. Wideband circularly polarized antenna with L-shaped slot. IEEE Transactions on Antennas and Propagation, 2008, vol. 56, no. 6, p. 1780-1783. DOI: 10.1109 /TAP.2008.923340

[7] PALANISAMY, V., GARG, R. Analysis of circularly polarized square ring and crossed strip microstrip antennas. IEEE Transactions on Antennas and Propagation, 1986, vol. 34, no. 11, p. 1340-1345. DOI: 10.1109/TAP.1986.1143766

[8] PITRA, K. RAIDA, Z., LACIK, J. Low-profile circularly polarized antenna exploiting Fabry-Perot resonator principle. Radioengineering, 2015, vol. 24, no. 4, p. 898-905. DOI: $10.13164 /$ re. 2015.0898

[9] IWASAKI, H. A circularly polarized small size microstrip antenna with cross slot. IEEE Transactions on Antennas and Propagation, 1996, vol. 44, no. 10, p. 1399-1402. DOI: 10.1109/8.537335

[10] ANANTHA BHARATHI, LAKSHMINARAYANA MERUGU, PVD SOMASEKHAR RAO. A novel single feed frequency and polarization reconfigurable microstrip patch antenna. $A E U$ International Journal of Electronics and Communications, 2017, vol. 72, p. 8-16. DOI: 10.1016/j.aeue.2016.11.012

[11] WONG, K. L., LIN, Y. F. Circularly polarized patch antenna with tuning stub. Electronics Letters, 1998, vol. 34, no. 9, p. 831-832. DOI: 10.1049/el:19980593

[12] ROW, J. S., AI, C. Y. Compact design of single-feed circularly polarized patch antenna. Electronics Letters, 2004, vol. 40, no. 18, p. 1093-1094. DOI: 10.1049/el:20045602

[13] SHARMA, V., SHARMA, M. M. Dual band circularly polarised modified rectangular patch antenna for wireless communication. Radioengineering, 2014, vol. 23, no. 1, p. 195-202.

[14] NASIMUDDIN, QING, X., CHEN, Z. N. Compact circularly polarized symmetric-slit microstrip antennas. IEEE Antennas and Propagation Magazine, 2011, vol. 53, no. 4, p. 63-75. DOI: 10.1109/MAP.2011.6097287

[15] KIROV, G. S., MIHAYLOVA, D. P. Circularly polarized aperture coupled microstrip antenna with resonant slots and a screen. Radioengineering, 2010, vol. 19, no. 1, p. 111-116. 
[16] SHAHIN SHEIKH, Circularly polarized meshed patch antenna. IEEE Antennas and Wireless Propagation Letters, 2016, vol. 15, p. 352-355. DOI: 10.1109/LAWP.2015.2445836

[17] TORRES, A. E., MARANTE, F., TAZÓN, A., et al. New microstrip radiator feeding by electromagnetic coupling for circular polarization. AEU-International Journal of Electronics and Communications, 2015, vol. 69, no. 12, p. 1880-1884. DOI: 10.1016/j.aeue.2015.09.016

[18] SHANMUGANANTHAM, T., RAGHAVAN, S. Novel printed CPW-FED slot antenna for wireless applications. Microwave and Optical Technology Letters, 2010, vol. 52, no. 6, p. 1258-1261. DOI: $10.1002 / \mathrm{mop} .25210$

[19] DENG, J. Y., YIN, Y.-Z., HUANG, Y. H., et al. Compact circularly polarized microstrip antenna with wide beam width for compass satellite service. Progress In Electromagnetics Research Letters, 2009, vol. 11, p. 113-118. DOI: 10.2528/PIERL09080801

[20] REDDY, V. V., SARMA, N.V.S.N. Compact circularly polarized asymmetrical fractal boundary microstrip antenna for wireless applications. IEEE Antennas and Wireless Propagation Letters, 2014, vol. 13, p. 118-121. DOI: 10.1109/LAWP.2013.2296951

[21] ZE-KUN PAN, WEI-XIN LIN, QING-XIN CHU. Compact widebeam circularly polarized patch antenna with a parasitic ring for CNSS application. IEEE Transactions on Antennas and Propagation, 2014, vol. 62, no. 5, p. 2847-2850. DOI: 10.1109/TAP.2014.2307348

[22] PRAKASH, K. C., MATHEW, S., ANITHA, R., et al. Circularly polarized dodecagonal patch antenna with polygonal slot for RFID applications. Progress In Electromagnetics Research C, 2016, vol. 61, p. 9-15. DOI: 10.2528/PIERC15110301

[23] LEI ZHONG, JING-SONG HONG, HONG-CHENG ZHOU. A dual-fed aperture-coupled microstrip antenna with polarization diversity. IEEE Transactions on Antennas and Propagation, 2016, vol. 64, no. 10, p. 4524-4529. DOI: 10.1109/TAP.2016.2589965

[24] LI, J GUO, J., ZHANG, A., et al. Miniaturized single-feed crossaperture coupled circularly polarized microstrip patch antenna. Progress In Electromagnetics Research C, 2016, vol. 63, p. 183 to 191. DOI: $10.2528 /$ PIERC16031301

\section{About the Authors...}

Naresh K. DARIMIREDDY (corresponding author) received B.Tech. from NBKRIST in ECE, M.E. (EC) from UVCE (A), Bangalore University, MBA from Central University Pondicherry and is presently pursuing $\mathrm{Ph} . \mathrm{D}$ from UCEK (A), JNTU, Kakinada. Associate Professor, Lendi IET, VZM. He has 14 years of industry and teaching experience. Member of IEEE, IEEE A \& P Society and IE.UGC-NET Qualified in 2013. He had 28 technical publications in reputed journals and international conferences. Research interests include microwave antennas, DRAs and microstrip filters.

R. RAMANA REDDY received M.Tech (I\&CS) in 2002 from JNTUK, Kakinada, MBA from AU in 2007 and Ph.D. in 2008 in Antennas from AUCE (A), AU. Professor and HOD of ECE in MVGRCE, VZM. Co-ordinator of Center of Excellence in Embedded Systems and NI Lab VIEW academy in MVGRCE. Published 75 technical papers in journals and conferences. Senior Member of IEEE, Fellow of IE, member of IETE and ISTE. His research interests include antennas, EMI/EMC, VLSI and embedded systems.

A. MALLIKARJUNA PRASAD Professor of ECE, and Vice Principal, UCEK (A), JNTUK, Kakinada. He received his Ph.D. from JNTUH in antennas. He worked as Head, Department of ECE and Controller of Examinations in JNTU-K. His research interests include microwave antennas, wireless communications and biomedical instrumentation. 